\title{
Distinguishing genetics and eugenics on the basis of fairness
}

\author{
Fred D Ledley Baylor College of Medicine, Houston, Texas, USA
}

\section{Author's abstract}

There is concern that human applications of modern genetic technologies may lead inexorably to eugenic abuse. To prevent such abuse, it is essential to have clear, formal principles as well as algorithms for distinguishing genetics from eugenics. This work identifies essential distinctions between eugenics and genetics in the implied nature of the social contract and the importance ascribed to individual welfare relative to society. Rawls's construction of 'justice as fairness' is used as a model for how a formal systems of ethics can be used to proscribe eugenic practices. Rawls's synthesis can be applied to this problem if it is assumed that in the original condition all individuals are ignorant of their genetic constitution and unwilling to consent to social structures which may constrain their own potential. The principles of fairness applied to genetics require that genetic interventions be directed at extending individual liberties and be applied to the greatest benefit of individuals with the least advantages. These principles are incompatible with negative eugenics which would further penalize those with genetic disadvantage. These principles limit positive eugenics to those practices which are designed to provide absolute benefit to those individuals with least advantage, are acceptable to its subjects, and further a system of basic equal liberties. This analysis also illustrates how simple deviations from first principles in Rawls's formulation could countenance eugenic applications of genetic technologies.

\section{Introduction}

It is difficult to consider the ethical or social implications of modern genetics without confronting the potential eugenic implications of these technologies $(1,2,3,4)$. Western society remains suspicious of genetic manipulation; haunted by the spectre of the holocaust and the a posteriori recognition of society's acquiescence to this most systematic and premeditated of modern atrocities. Concern about eugenics is reinforced by the perception that racism and prejudice continue to influence public policy, as

\section{Key words}

Genetics; eugenics; medical genetics; justice as fairness. well as persistent popular sympathy for seemingly eugenic notions espoused by various nationalist, ethnic, religious, or economic doctrines. It is a concern reinforced by the knowledge of the ethnic cleansing in the Balkans. Geneticists and ethicists are also aware that many modern institutions of genetics evolved directly from those of eugenics $(5,6)$.

Some social commentators believe that modern genetic technologies could foster a new era of eugenics, and that the only way to prevent these technologies from becoming tools of eugenic discrimination is to restrict, or even ban, their applications to humans. To deny the application of modern genetics to human problems, however, also denies a therapeutic and egalitarian potential; one which may be used to prevent pain, suffering, and premature death in those who are afflicted by disease; and one which may be used to ameliorate the differences between those born with congenital handicaps and those fortunate to be born with the full spectrum of human potentials.

If we are to harvest the healing potential of molecular genetics without risking a renewal of eugenic abuse, we must identify formal boundaries between genetics and eugenics and establish formal mechanisms for judging whether proposed interventions are eugenic in their nature. It is not sufficient to have good intentions. We must build fences between the traditional path of medical therapeutics and the much-feared slippery slope of eugenic exploitation.

The premise of this essay is that there are formal philosophical differences between genetics and eugenics. These differences are apparent in the implied nature of the individual's relationship with society and the significance ascribed to the individual in measuring the well-being of society. This essay explores whether it is possible to formulate an ethical basis for human genetics which recognizes these fundamental distinctions between genetics and eugenics.

\section{The definition of eugenics}

The term 'eugenics' has many connotations, ranging from genocide, to the genetically programmed births 
of Huxley's Brave New World, to forced sterilization of individuals thought to be 'defective', to common forms of social prejudice and discrimination. Sir Francis Galton, the founder of eugenics, provided a classic working definition of eugenics in his endowment of the Galton chair in Eugenics at University College, London:

'The study of aegis under social control that may improve or impair the racial qualities of future generations either physically or mentally' (7).

While the terminology used in Galton's definition is somewhat archaic, this definition is consistent with common dictionary definitions of eugenics such as:

'a science that deals with the improvement of hereditary qualities in a series of generations of a race or breed especially by social control of human mating or reproduction' (8).

These definitions of eugenics describe both 'negative eugenics', involving discrimination against the reproduction of individuals with perceived handicaps, and 'positive eugenics', involving manipulations to increase the fraction of people presumed to have superior inheritance. It should be noted that these formal definitions of eugenics may not subsume the colloquial use of the term eugenics as a synonym for many forms of social discrimination. It should also be noted that Galton's usage of the word 'racial' in the context of eugenics should be considered synonymous with the word 'genetic', which had not at that time been coined, and is not an explicit reference to racial groups.

Two aspects of these definitions can be used to differentiate genetics and eugenics. First, what aspects of genetics are properly under social control? Do they include reproductive freedoms, free association in marriage, privacy in childbearing decisions, or survival to (or beyond) childbearing age? Second, how are 'racial qualities' measured? Is the appropriate measure a statistical distribution of a population, or is it a measure of the individual characteristics or capabilities shared by all citizens? These two aspects will be addressed in the succeeding sections.

\section{Eugenics and the social contract}

The first difference between eugenics and genetics arises from the assumed nature of social control. The fear that modern genetic technologies could become an instrument of eugenic practices relates largely to the concern that genetics may contribute to institutionalized discrimination, social prejudice, or legislated limitations on individual rights.

The nature of social control is obviously a major issue in western philosophy. While this issue is generally addressed in the context of separating the rights and responsibilities of governments and their $\stackrel{m}{\vec{t}}$ citizens, the same logical structures which define the boundary between the legitimate and illegitimate $\ddot{\Rightarrow}$ extensions of the state may be applied in considering $\stackrel{5}{?}$ the boundary of social control over the individual's genetic constitution and procreation. Without $\frac{\bar{\sigma}}{\bar{g}}$ reviewing the many important constructions of the $\frac{\bar{s}}{\vec{\phi}}$ social contract, it may be generalized that systems $\stackrel{\mathbb{Q}}{\Omega}$ which emphasize the right of the sovereign \& governments, incorporated body politic, or demo- $\vec{\circ}$ cratic majority, to impose policies on individuals in the interest of the perceived general welfare often $\vec{\omega}$ assume a considerable degree of social control over genetic liberties. Galton's assumption that there exist social controls which may be used to alter the characteristics of the population is not incompatible with social practices which countenance social control over marriage across racial, ethnic, or $\mathcal{V}$ religious boundaries, family size, birth control, 옥 immigration, or emigration.

Even in the liberal democratic societies of the $c$ west, which traditionally emphasize the free will and $\frac{\mathbb{D}}{O}$ rights of the individual, eugenic doctrines were widely accepted during the first half of this century and contributed to overtly eugenic social policies concerning miscegenation, immigration, and $\overrightarrow{0}$ involuntary sterilization. There remains considerabe apprehension about the safety of genetic liberties. Many view the social Darwinist tendencies of the unrestricted free market to be a form of eugenics. Some view society's inattention to the disproportionate infant mortality rate and reduced life expectancy of minority groups as a form of passive $\overrightarrow{\vec{F}}$ eugenics (4). For many, the resurgence of ethnic intolerance, anti-semitism and fascism, along with nationalism in post-communist Europe, makes very real the possibility that nationalist, ethnic, or even religious movements could come to sanction overtly

eugenic principles.
While medical genetics, unlike eugenics, does not presuppose the existence of any form of $\delta$ institutionalized social control over genetic liberties, $₹$ certain aspects of medical care and practice are 으 sometimes accused of being potentially eugenic. For $>$ example, there is fear that insurance companies and employers could become agents of eugenic practices if information from genetic testing is unprotected. O There is also fear that legislation which limits access $\tilde{O}$ to health care for certain diseases could be a form of $N_{\omega}^{N}$ eugenics.

Is there a genuine risk of contemporary philosophy, ethics, and jurisprudence sanctioning $\frac{}{\varnothing}$ social control over genetic liberties? This question $\stackrel{f}{+}$ must be answered by critically assessing the $\square$ principles which underlie the social contract, and by asking whether the philosophical structures which $\stackrel{D}{\overparen{D}}$ define the powers of the state and society over the $\stackrel{\mathbb{Q}}{\circ}$ individual offer sufficient protection for individual $\frac{}{0}$ rights in the face of genetic knowledge and capabilities. 


\section{The quality of future generations}

The second important distinction between genetics and eugenics resides in the algorithms used to measure the quality of future generations. Classical eugenics was concerned with a biometric analysis of the mean and variance of a population. In contrast, modern medical genetics is predicated upon a model of allopathic therapeutics aimed at alleviating the afflictions of individuals. The essence of allopathic medicine is that the individual is autonomous, rather than synonymous with his or her disease, and that treatment is directed at eliminating disease and maximizing the repertoire of individual opportunity and ability.

In a previous paper, I described how Lionel Penrose, a physician and the fourth Galton Professor of Eugenics, abandoned eugenic doctrine, when he recognized the potential for treating mental retardation caused by inherited diseases such as phenylketonuria (9). Penrose did not abandon eugenics because he considered concern with the character of future generations to be unethical, but because it became apparent that it was more efficacious to deal with the disabled as individuals with medical afflictions. The allopathic principle of improving the capabilities of individuals with afflictions replaced the eugenic goal of improving society by eliminating members with lesser qualities (negative eugenics) or enhancing the numbers or capabilities of the elite (positive eugenics).

In applying the paradigm of allopathic medicine to genetics, Penrose also implicitly assumed the ethical precepts and precedents of western medicine in which the interests of individual longevity, wellbeing, and privacy take precedence over the interests of society. Risk and benefit are defined with reference to individuals, their freedom of expression, and their free will. Are contemporary genetic practices allopathic in nature? Are the guidelines of allopathic practice useful instruments for preventing eugenic abuse?

Somatic gene therapy and screening of the newborn for treatable inherited or congenital diseases are classic applications of the allopathic model for treating human disease. Other potential genetic practices such as preconception, or population, screening for heterozygous carriers of mutations, prenatal diagnosis for untreatable diseases, or the use of genetic technologies to enhance normal capabilities, are not classically allopathic in nature.

\section{The ordered principles of fairness}

The preceding sections have attempted to establish basic principles which distinguish eugenics and medical genetics. The question then is whether formal philosophical, ethical, and legal principles can constitutively discriminate between genetic and eugenic applications of modern technologies, enabling genetic applications to proceed without risk of eugenic abuse. The preceding analysis suggests that the essence of this question relates to the perceived influence of individual liberties relative to that of the society, as well as to the perceived importance of individual welfare relative to that of the population.

John Rawls's formulation of the relationship between individual liberty and the social order in his influential book, $A$ Theory of fustice (10), provides one model for addressing this question in a formal manner. Rawls's theory of 'justice as fairness' is based upon reconsideration of a theoretical original position in which no social structures are presumed to exist among men. From this condition, Rawls reconstructs how social structures could be voluntarily created among individuals possessed of rationality, reflective equilibrium, and free will. The critical postulates in Rawls's synthesis are: i) that in the original condition all individuals are equal, or at least enshrouded in a 'veil of ignorance' which makes individuals unaware of their potential inequality, and ii) that no one would consent to structures which compromise his/her personal prospects or prosperity. From these postulates, Rawls derives a set of ordered principles which can serve as a basis for justice (10):

First principle: Each person is to have an equal right to the most extensive total system of equal basic liberties compatible with a similar system of liberty for all.

Second principle: Social and economic inequalities are to be arranged so that they are both:

(a) to the greatest benefit of the least advantaged, consistent with the just savings principle, and

(b) attached to office and positions open to all under conditions of fair equality of opportunity. First priority rule: The principles of justice are to be ranked in lexical order and therefore liberty can be restricted only for the sake of liberty. There are two cases:

(a) a less extensive liberty must strengthen the total system of liberty shared by all, and

(b) a less than equal liberty must be acceptable to those citizens with the lesser liberty.

While Rawls's construction is explicitly designed to address social and economic justice, his formulation is applicable to the issues raised by modern genetics. The logic of Rawls's argument, the ordered principles of justice as fairness, and the terms of the contract which Rawls constructs between man and society may be formally applied to genetics by adducing the initial conditions that all individuals are genetically equal, or at least ignorant of their genetic constitution and its consequences for their progeny. Following the essence of Rawls's argument, it may be deduced that no individual would accept genetic manipulations which alter the postulate of genetic equality of the initial condition 
for fear that his/her own prospects could be diminished. Rawls himself suggests this line of reasoning, writing:

'There is also, theoretically anyway, the question of a reasonable genetic policy. In these cases too, in order to carry through the idea of the original position, the parties must not know the contingencies that set them in opposition. They must choose principles the consequences of which they are prepared to live with whatever generation they turn out to belong to' (11).

Applying the path of Rawls's logic to the problem of genetics, a set of ordered principles might be derived which could guide the application of genetics in accordance with the principles of fairness. Paraphrasing Rawls's ordered principles, genetic applications should: i) affirm the priority of the individual's right to extensive, equal basic liberties over any application of genetic technologies [First principle]; ii) provide absolute benefit for the least advantaged [Second principle, a]; iii) make the opportunities and benefits which may accrue from genetic applications available without discrimination [Second principle, $b$ ]; iv) maximize the minimum level of opportunity or potential shared by all (the social minimum), rather than maximize the average liberties [First priority rule, a]; and v) ensure that genetic inequalities and genetic interventions are acceptable to those with genetic disadvantages [First priority rule, $b]$. Note that this construction addresses only issues of social control and individual liberties and is not dependent upon general theories of health care based on Rawls's philosophy (12).

Rawls's construction of a theory of justice is a particularly appropriate model for considering the issues raised by genetics and eugenics because humankind is, in many respects, truly in an original position with respect to the formulation of social structures regarding genetics. We are, in fact, ignorant of our own genetic potential. Moreover, Rawls's formulation specifically addresses the two basic issues which distinguish genetics and eugenics by: i) defining the basis and limits of social control over individual liberties, and ii) emphasizing the need to focus on minimal individual welfare in assessing the ethics of societal actions. The paraphrased principles of fairness explicitly proscribe the practice of negative eugenics which is not directed at furthering a 'system of equal basic liberties compatible with a similar system of liberty for all', is not 'to the greatest benefit of the least advantaged', and is directed at strengthening a statistical measure of opportunity rather than the objective opportunities (liberties) shared by all, specifically those with the least advantages.

The application of these principles to positive eugenics is more complicated, given the nature of the arguments which are often used to justify such positive eugenic practices. It might be argued that positive eugenics could indirectly benefit those with the least advantage, creating more opportunities and thus enhancing their freedoms, and that the principles of fairness would, therefore, not explicitly proscribe positive eugenics. This line of reasoning is central to Rawls's broad theory of justice, in which social and economic inequalities are justified by their extended effects on the system of basic liberties and, specifically, by their ability to extend the liberties of those with the least advantages. Does such reasoning justify positive eugenics?

\section{Historical precedents}

In assessing the fairness of positive eugenic practices, it is necessary to ask whether it is reasonable to assume that genetic inequalities truly benefit those $\omega$ with the least advantage. Historical precedents $\vec{v}$ suggest that genetic inequalities rarely, if ever, $O$ benefit those who are disadvantaged. On the contrary, it is common to make a distinction $\vec{c}$ between those whose evident disadvantages are $\mathbb{D}$ genetically determined and those whose dis- $\mathbb{D}$ advantages are social or acquired (ie, nature versus nurture). The purpose of this distinction has $\stackrel{\mathbb{C}}{-}$ historically been to delineate those who are simply $\vec{\theta}$ socially or economically disadvantaged, who mas benefit from social interventions such as education welfare, or economic growth, from those who as genetically disadvantaged, who may not warrant (or may not benefit from) such interventions. It is historically common to predicate social and political discrimination against certain social or economic groups on the basis of their presumed genetic disadvantage. For example, the eugenic characterization of Jews, blacks, and indigenous peoples of the new worlds played an important role in justifying racist policies within the philosophically liberal societies of Western Europe and America. In this context, positive eugenic applications which increase the real or apparent inequalities among individuals would be perceived as a real peril to those with the least advantage.

It is also unclear how genetic inequalities, in contrast to social or economic inequalities, might $\frac{D}{O}$ lead to tangible benefits for those who are genetically disadvantaged. Rawls justifies social and economic $\tilde{N}$ inequalities on the basis of the supposition that $N$ economic growth and social opportunities which N may derive from the accumulation of wealth may $\omega$ subsequently provide material benefit for those who are disadvantaged. This benefit is accrued through the investment in social and economic structures $\stackrel{\odot}{\oplus}$ which are themselves subject to the principles of fairness. While it may be argued that social and 0 economic benefit may accrue indirectly from $\mathbb{D}$ positive eugenics (this is the classic justification of $\frac{?}{\mathbb{1}}$ eugenics by Galton and his contemporaries), there is $\varrho$ little social or historical precedent for such beneficial effects. It is also unclear whether social structures 
currently exist which may exploit such inequalities for the benefit of the disadvantaged in the same way that the generation of wealth is presumed to expand the opportunities for the poor. Thus, it is unlikely that such practices would meet the criteria of fairness.

In the original condition, in which the postulate of genetic equality is essential, it can be surmised that the possibility of indirectly benefiting from positive eugenics would be less compelling than the potential for introducing discrimination based on the imposition of genetic inequalities. On a theoretical basis, positive eugenic practices which introduced genetic inequalities would, thus, be proscribed by the ordered principles of fairness both because it would not further an equal basic liberties and, given the lessons of history, would be unlikely to be acceptable to those with lesser liberties.

\section{Practical applications of fairness}

Are the ordered principles of fairness which Rawls proposes useful for adjudicating specific applications of modern genetics? This question may be asked at two levels. The first is whether Rawls's paraphrased principles of fairness can be used to delineate genetic interventions which are fair, from those which are potentially eugenic in nature. This is the question addressed by the present work. The second level concerns the question of whether Rawls's formulations can be used to measure the ethics, propriety, and social utility of specific genetic interventions. This question is beyond the scope of this present work and will be addressed only tangentially.

It is not difficult to apply Rawls's principles of fairness to evaluating essentially allopathic practices of medical genetics such as somatic gene therapy (9). Here the explicit intent of the genetic interventions are to benefit those individuals who are least advantaged such as those with genetic diseases or handicaps which might be rectified by genetic interventions. Rawls's principles of fairness stipulate that such applications be applied without discrimination, with equality of opportunity, and with the acceptance of the subject. These conclusions are not uniquely dependent upon Rawls's principles of fairness. For example, the primary importance of distinguishing interventions which aid those with handicaps, ensuring equal access to genetic therapy, and obtaining voluntary and informed consent have been strongly affirmed by various ethicists, religious groups, and government policy committees in establishing regulations for somatic gene therapy $(13,14,15,16,17)$.

The application of the principles of fairness to analyze actions which would enhance normal characteristics (ie, by positive eugenics) is more complex. Why not use genetics to enhance the talents of gifted athletes? Why not use genetic interventions to improve intelligence or work performance? Why not use genetic interventions to enhance the normal life-span? While some of these genetic applications are ostensibly benign, it is likely that none of these applications would satisfy the conditions of fairness by providing absolute advantage and being acceptable to those with the least advantage. For example, enhancing the athletic ability of athletes would not be acceptable to their lesser opponents. Improving the intelligence or work performance of some individuals would not be acceptable to those who might compete for their jobs. Enhancing the normal life-span would not be acceptable to younger individuals or future generations who would most likely suffer diminished opportunities. Each of these measures would, in practice, further inequalities in opportunity without a tangible prospect of benefiting those who remain at a disadvantage or furthering a state of equal basic liberties.

The issue of using genetic engineering to facilitate longevity illustrates how the principles of fairness can be used to distinguish eugenic and non-eugenic applications of similar technologies. While longevity has been significantly increased in recent decades by the pharmacological treatment of disease, by adequate nutrition, and by good sanitation, these measures are not considered eugenic since they are specifically designed for the benefit of individuals who are afflicted by disease, poor nutrition, or poor hygiene. So too, the use of genetic technologies to minimize the morbidity of ageing, to treat or prevent disease, or protect individuals from environmental or work-related toxins would provide absolute benefit of the least advantaged (ie, those at risk) and would be acceptable to those with disadvantage. Such practices would be entirely consistent with the principles of fairness even if they coincidentally provided benefits to those who were not disadvantaged.

In contrast, the use of genetic engineering to enhance longevity in normal individuals would create further constitutive inequalities within the population, distancing those whose longevity would be increased from those whose longevity was limited by disease or other factors. Such applications would not inherently further a system of equal basic liberties, would not objectively benefit those with the least advantage or receive their acceptance, and thus would be incompatible with the ordered principles of fairness.

The critical point is that the distinction between eugenics and medical genetics does not relate to the nature of the technology which may be used to enhance longevity, but rather in the purpose for which such technologies are applied. Genetic engineering is not more inherently eugenic than birth control, sterilization, or family planning which can each be employed fairly in medical practice, but also can be abused by society for eugenic purposes.

In applying the principles of fairness, one is formally making a distinction based on criteria 
which are similar to those used to distinguish genetics and eugenics. Those genetic interventions which are socially imposed in the beneficent interest of future generations meet the definition of eugenics and do not meet the standards of fairness. If the same interventions were applied in a manner consistent with fairness, they would not be eugenic because they would be based on the assent of individuals rather than on imposed social controls, and because they would focus on the needs of individuals rather than the statistical quality of the population.

It may be further generalized that the application of genetic technologies in the context of allopathic medicine (ie, to treat an individual afflicted with an undesirable or disadvantageous condition), in accordance with the ethical principles and precepts of allopathic medicine which require voluntary informed consent, would be compatible with fairness and are therefore not eugenic in nature. Some genetic applications such as genetic counselling, population screening, preconception screening, prenatal diagnosis, or germline gene therapy, however, are not obviously allopathic and are ambiguous when analyzed with regard to the ordered principles of fairness. The formal difficulty is that in order to apply the ordered principles of fairness it is necessary to identify the individual who may benefit from the genetic intervention (ie, in the context of fairness, the individual with lesser liberties for whom genetic intervention provides absolute advantage). Is genetic screening, for example, aimed at extending the liberties of a parent, an unborn child, a sibling, other relatives, or prospective conceptions in the future?

Even without being able to provide a general answer to this question for each conceivable case, it may be recognized that by applying the principles of fairness, the analysis assumes a distinct focus. If an individual can be identified who will benefit from the proposed genetic intervention in accordance with the ordered principles of fairness and who will provide assent, then that intervention is not eugenic in its application.

For the purposes of assessing whether or not an intervention is eugenic, it does not formally matter who is ultimately considered to be the subject of the genetic intervention. (The ethics of each action is obviously critically dependent upon the choices that are made between individuals, though this is not the topic of the present work). There are many precedents for this type of choice in medicine. A transplant surgeon may remove organs from a kidney donor to benefit a recipient, society may incarcerate a child-abuser to protect a child, and certain risks of genetic or infectious disease may be allowed to protect the privacy of a patient being treated for these conditions. In each of these practices, once the patient is identified, medical practice is governed by attention to the risks and benefit to the patient as an individual and the ability to obtain voluntary and informed consent from each participant.

\section{The fragility of fairness applied to genetics}

Rawls explicitly declines to consider eugenics in $A$ Theory of fustice, yet his tangential consideration of eugenics illustrates its eminent danger. In considering eugenics Rawls digresses from his presumption of social equality and postulates an essential genetic inequality, writing:

'... the distribution of natural assets is a fact of nature and that no attempt is made to change it, or even take it into account' (18).

and that:

'In the original position, then, parties want to insure $\vec{c}$ for their descendants the best genetic endowment' (19).

Based on these premises he derives principles which appear to countenance both 'negative eugenics' and 'positive eugenics':

'Thus over time a society is to take steps at least preserve the general level of natural ability and to prevent the diffusion of serious defects' (20).

It is striking that, in considering eugenics, Rawls temporarily denies one of the central tenets of his synthesis. He contradicts his assertion that '... all parties in the original position are equal ...' (20) by assuming the genetic distribution of assets (ie, genetic inequality) is a 'fact of nature'. Rawls's deference to genetic inequality over the general concept of human equality (or at least a veil of 3 . ignorance) perhaps merely cedes the obvious; that whatever the limits of personal prescience, most people remain confident that they can gauge their own genetic constitution relative to that of others.

Perhaps there is a practical limit to the theoretical presumption of equality or ignorance which is $\sigma$ transcended in considering one's own genes. The $N$ sense that there is a pragmatic limit to our $\underset{\mathcal{E}}{\mathbb{N}}$ acceptance of genetic equality is central to our fear of $\bar{O}$ eugenics. This sense is reinforced by centuries of history littered with ethnocentricity, racism, $\frac{0}{\Phi}$ nationalism, anti-semitism, slavery and genocide $\stackrel{\infty}{+}$ and the justification of such practices based on the 7 presumption of genetic inequality. It is threatened by $\bar{O}$ evolutionary theories which posit that evolution is $\mathbb{D}$ driven by the dissemination of 'superior' genes $\overrightarrow{\mathbb{D}}$ through populations or that the nature of the self and $\frac{\varrho}{\sigma}$ society can be shaped by selection among unequally fit genetic determinants (21). 
It is not necessary, however, to rewrite history or reject modern evolutionary theory to resurrect fairness as a basis for genetic ethics. It is not even necessary to accept the counterintuitive contingency that individuals are in any real sense genetically equal. Certainly there are genetic differences between different individuals, different races, and even different ethnic groups. Certainly many individuals are genetically disadvantaged. Yet molecular genetic analysis illustrates that these genetic differences are superficial, and that we are more equal than supposed by appearance (22). We are, in fact, almost completely ignorant of our genetic constitutions and our fate. Every individual carries dozens of potentially lethal mutations and hundreds of genes which may contribute to malformation or disease. Some of these mutations cause disease during embryonic development, childhood, or adulthood; some are associated with disorders of reproduction, senescence or cancer; some will affect only our progeny and kin. Those individuals who suffer from genetic disease do not necessarily have more mutant genes than those who are apparently normal. For example, a child with cystic fibrosis does not have more mutant genes than a child who is unaffected; rather, in the affected child, two of the dozens of potentially lethal mutations happen to fall within the cystic fibrosis locus, while in an unaffected child, mutations may be found scattered elsewhere in the genome. Moreover, with every conception, our offspring are at risk for novel chromosomal abnormalities such as Down's syndrome or spontaneous mutations which are the most common cause of diseases such as muscular dystrophy, Lesch Nyhan disease, and most severe autosomal dominant diseases. Others carry 'pre-mutations' in the form of unstable repetitive sequences that are prone to disease-causing mutation.

One of the most important discoveries of genetic research is the recognition that each individual carries uncountable novel genetic excursions which constitute the rich potential of human variability. It is estimated that up to one per cent of all bases in the human genome are variable among different individuals. A small subset of these variations cause recognizable diseases such as cystic fibrosis, phenylketonuria, muscular dystrophy, or haemophilia. There are currently 3,000-10,000 known disorders which are due to specific genetic variations within the human genome (23). It is known, however, that there are over $30,000,000$ other variations which occur within the human genome, most of which cannot be conveniently categorized as normal or abnormal. For example, we have learned that even mutations which cause recognizable diseases such as sickle cell anaemia, phenylketonuria, or cystic fibrosis can confer an evolutionary advantage on their carriers in other climates and social conditions. The sickle cell gene may provide protection against malaria, phenylketonuria may not be a disease in societies which have limited protein intake, and the common cystic fibrosis mutation encodes a protein which may function at low temperatures. In contrast, certain genetic variations which are considered benign or even beneficial today could be recognized as pathogenic under different environmental or cultural conditions in the future.

The crucial point is that we do not know, and indeed cannot know, the quality or value of the remarkable variability within the human genome. That is not to say that we cannot recognize diseases and disadvantage caused by genetic mutation; only that we cannot rationally surmise that our genetic endowments are inherently unequal (22). We do not know the long-term significance of our own genetic endowment, and we cannot know whether genetic diagnosis, genetic screening, or genetic therapy will ultimately improve or impair our own position or that of our progeny. Thus, it seems reasonable to invoke the verity of a 'veil of ignorance' with respect to genetics, and, in the original condition accept the presumption of equality in the absence of any objective evidence to the contrary. We can only hope that we are, in fact, equal and equally fit for the future. We must retain the presumption of equality as an initial condition in considering the ethics of genetic technologies. It should be emphasized that this presumption of equality, not the demonstration of true equality (which may be doubted by many), is sufficient to satisfy Rawls's definition of the original condition and apply the principles of fairness to proscribing eugenic practices.

\section{Conclusion}

This analysis demonstrates that genetics and eugenics can be formally distinguished by their contrasting assumptions concerning the relationship between the individual and society, and suggests that a social contract can be adequately formulated to project these distinctions into practical ethical and legal principles. This analysis also illustrates the fragile nature of this synthesis and how eugenics may be countenanced by subtle changes in essential postulates.

The fair and ethical application of genetics is critically dependent upon assumptions concerning the extent of essential individual rights and essential human equality. The doctrines of many nationalist, ethnic, and religious movements; many conservative constructions of social philosophy; the immortal presumptions of many mortal men; and even the estimable goals of medical diagnosis, education, and therapy often appear to trespass down the 'slippery slope' towards eugenics. The fence that separates the path of medical genetics from this 'slippery slope' is our willingness to accept the postulate of essential 
genetic equality and priority of individual freedoms. If there is any compromise of individual rights relative to those of society, if there is any willingness to consider the quality of future generations in aggregate rather than as the minimal shared level of individual well-being, or if any presumption of genetic inequality is not vigorously disallowed, then it is not difficult to rationalize eugenic programmes. If, however, genetic applications focus resolutely on preserving or extending explicit individual liberties with the assent of the individuals concerned, then eugenic abuse is impossible.

To avoid even accidental usurpation of genetic technologies for eugenic purposes, each application of genetics to medicine must clearly identify an individual (whether it is an adult, a child, or parent) whose affliction is the target of therapy, specific individual liberties which are reinforced by each genetic intervention, and evidence that the assent of the individual has been obtained. Genetic diagnosis, patient education and medical records must be carefully formulated so that those who have the opportunity to peer beyond the veil of ignorance appreciate the critical postulate of human equality. This must be done carefully to protect both our patients and their progeny.

\section{Acknowledgement}

I would like to thank Drs L S Rothenberg, Baruch Brody, and Andrew Lustig for their comments on this work as well as the anonymous referees of this journal for their thoughtful critique.

Fred D Ledley, $M D$, is an Associate Professor of Cell Biology and Pediatrics at the Baylor College of Medicine as well as a founder and Vice President, Clinical and Regulatory, GENEMEDICINE, INC. He received a BS degree from the University of Maryland (1974), an MD from Georgetown University (1978), trained in Pediatrics at the Harvard Medical School and Boston Children's Hospital (1978-1981), and trained in molecular biology at the Massachusetts Institute of Technology with Dr David Baltimore (1981-1983).

Dr Ledley was principal investigator of the first approved clinical trial for somatic gene transfer into the liver of human subjects. He is the author of over 150 papers or chapters related to various aspects of the molecular biology of human disease, somatic gene therapy, and clinical application of genetic engineering to man. He is cochairman of the Houston Study Group on Genetics, Religion, and Ethics at the Institute of Religion of the Texas Medical Center.

Address for readers' correspondence: Fred D Ledley, $\overrightarrow{\bar{ज}}$ MD, Associate Professor, Departments of Cell Biology and Pediatrics, Baylor College of Medicine, One Baylor Plaza, Houston TX 77030, USA.

\section{References}

(1) Holtzman N A. Proceed with caution. Baltimore: Johns Hopkins University Press, 1989.

(2) Rifkin J. Algeny. New York: Viking Press, 1983.

(3) Friedmann T. Gene therapy, fact and fiction. Cold Spring Harbor: Cold Spring Harbor Laboratory Press, 1983.

(4) Duster T. Backdoor to eugenics. New York: Routledge, 1990.

(5) Kevles D J. In the name of eugenics. New York: Alfred A Knopf, 1985.

(6) Gould S J. The mismeasure of man. New York: W W Norton, 1981.

(7) See reference (5): 37

(8) Webster's third international dictionary. Springfield, MA: G C Merriam Co, 1961: 783.

(9) Ledley F D. Somatic gene therapy for phenylketonuria; a problem of eugenics? Trends in genetics 1987; 1: 309-313.

(10) Rawls J. A theory of justice. Cambridge, MA: Harva University Press, 1971: 32.

(11) See reference (10): 137.

(12) Daniels N. Fust health care. Cambridge, England: Cambridge University Press, 1985.

(13) Nelson J R. The role of religions in the analysis of the ethical issues of human gene therapy. Human gene therapy $1990 ; 1: 43-48$.

(14) Walters L. The ethics of human gene therapy. Nature 1986; 320: 225-227.

(15) Murray T H. Human gene therapy, the public, and the public policy. Human gene therapy 1990; 1: 49-54.

(16) Fletcher J C. Evolution of ethical debate about human gene therapy. Human gene therapy 1990; 1: 55-68.

(17) Ledley F D. Clinical considerations in the design of protocols for somatic gene therapy. Human gene therapy 1991; 2: 77-84.

(18) See reference (10): 107.

(19) See reference (10): 108.

(20) See reference (10): 109.

(21) Wilson E O. On human nature. Cambridge, MA: Harvard University Press, 1979.

(22) Lewonton R. Human diversity. New York: Scientific O American Books, 1982.

(23) McKusick V. Mendelian inheritance in man. N Baltimore: Johns Hopkins University Press, 1989. 